\title{
Sequência didática sobre impacto ambiental alinhada aos parâmetros curriculares nacionais
}

\section{Didactic sequence on environmental impact aligned with the national curriculum parameters}

\author{
${ }^{1}$ Vanessa Regal Maione Jeovanio-Silva vanmjs@gmail.com \\ 1 Sheila Pressentin Cardoso \\ ${ }^{2}$ André Luiz Jeovanio-Silva
}

\section{RESUMO}

O trabalho apresenta o desenvolvimento e a avaliação de uma sequência didática (SD) abordando o tema impacto ambiental, organizada de forma adequada aos Parâmetros Curriculares Nacionais, visando a ofertar aos professores um material que auxilie na realização de atividades de forma prática, transversal e lúdica, destinada ao ensino fundamental. A pesquisa, de natureza qualitativa e participante, contou com a participação de professores formados em ciências biológicas, física, química e matemática, com a coleta de dados envolvendo a aplicação de questionário e entrevista. A SD foi desenvolvida contendo cinco etapas que apresentam o problema abordado, os objetivos das etapas, os temas que podem ser abordados, os recursos e materiais necessários, os procedimentos para as atividades propostas e sua duração. As atividades envolveram o uso de vídeo, debate, experimentos e mostra artística. Os docentes consideraram as etapas bem elaboradas, com aspectos didáticos e informações que permitem que sejam realizadas com facilidade e segurança, envolvendo temas atuais e pertinentes aos conteúdos do nível fundamental e promovendo um ensino contextualizado às demandas da sociedade.

Palavras-chave: Impacto ambiental. Educação ambiental. Sequência didática.

\begin{abstract}
This paper presents the development and evaluation of a didactic sequence (DS) approaching the environmental impact organized in accordance with the National Curriculum Parameters aiming to provide teachers a material that helps them to perform activities in a practical, transversal and playful way, destined for middle school. The qualitative and participant research was performed relying on teachers with licentiate degree in biological sciences, physics, chemistry and mathematics, using questionnaire and interview to data collection. The DS was developed containing five stages that present the problem addressed, the objectives of the stages, the topics that can be approached, the resources and materials needed, the procedures for the proposed activities and their duration. The activities involved the use of videos, debates, experiments and art activities. The teachers considered that the stages were well elaborated, with didactical aspects and information that allows carrying out stages with easy and safety, involving current themes that are pertinent to the middle school content knowledge and providing a contextualized learning.
\end{abstract}

Keywords: Environmental impact. Environmental education. Didactic sequence.

1 Instituto Federal de Educação, Ciência e Tecnologia do Rio de Janeiro, campus Nilópolis (IFRJ), Programa de Pós-Graduação em Ensino de Ciências (PROPEC).

2 Instituto Nacional de Propriedade Industrial - INPI. 


\section{INTRODUÇÃO}

Sequências Didáticas (SD) são ferramentas didático-pedagógicas que abrangem atividades construídas em torno de um tema central, e que buscam trabalhar habilidades e competências no aluno para que este possa identificar, compreender e propor possíveis soluções para determinados problemas e situações.

Segundo Oliveira (2013), SD é um processo no qual várias atividades são interligadas e planejadas para se obter um diferenciado processo de ensino-aprendizagem. Sua elaboração envolve a escolha de um tema central a ser trabalhado, seguido pelo planejamento das etapas e do tipo de atividades que farão parte de sua organização. Estas devem ser diversificadas para trabalhar as diferentes habilidades, competências e saberes que se deseja desenvolver, tornando mais eficiente e contextualizada a construção do conhecimento dos temas abordados, além de estreitar a interação entre os alunos, entre esses e o professor, e despertar o interesse dos alunos e do próprio docente pela atividade.

O tema central selecionado para o desenvolvimento da SD, objeto do presente estudo, foi "impacto ambiental”, termo definido pelo Conselho Nacional do Meio Ambiente (CONAMA) como sendo:

Qualquer alteração das propriedades físicas, químicas e biológicas do meio ambiente, causada por qualquer forma de matéria ou energia resultante das atividades humanas que, direta ou indiretamente afetam a saúde, a segurança e o bem-estar da população, as atividades sociais e econômica, as condições estéticas e sanitárias do meio ambiente, a qualidade dos recursos ambientais (BRASIL, 1986, art. 1º).

Esses efeitos podem acarretar danos diretos ou indiretos aos diferentes ambientes do planeta, com consequências para os seres vivos de diversos hábitats, afetando a saúde de todos, além de ter consequências econômicas e sociais em diferentes graus. A redução do impacto ambiental envolve uma conjuntura de mudanças que resulta de um complexo, rico e longo processo de aprendizado que envolve a construção de conhecimentos, desenvolvimento de visão em perspectiva ampla, olhar crítico e autocrítico, mudança de mentalidade e de comportamento que deve ser iniciado com os indivíduos o quanto antes for possível. Nesse contexto, torna-se primordial que as instituições de ensino tenham participação nesse processo e desenvolvam uma educação ambiental (EA) crítica abordada de forma transversal, trabalhando a integração e a multidisciplinaridade conforme definido pelos Parâmetros Curriculares Nacionais (PCN) (BRASIL, 1998).

Definido o tema, a construção da SD passa à seleção e ao planejamento das atividades a serem trabalhadas, envolvendo a elaboração das ações de cada atividade, as quais correspondem a um plano de aula que compreende a problemática a ser abordada, os objetivos que se pretende alcançar, os assuntos ou questões a serem tratados dentro da problemática escolhida, os materiais e recursos didáticos necessários. Dentre os recursos didáticos que podem compor as atividades tem-se o uso de vídeos, debates, jogos, experimentos, produção de maquetes, trabalhos de campo, confecção de trabalhos manuais e atividades que envolvam arte como música, teatro, dança, desenho, pintura, poesias, histórias em quadrinhos, contação de histórias, dentre outros.

Os recursos didáticos têm uma grande importância para o ensino, pois são ferramentas com potencial e capacidade de transformar um ensino tradicional e sem atrativos em um ensino inovador, tecnológico, contextualizado e integrado à realidade de um determinado grupo, sendo essencial compreender de forma clara as possibilidades e os limites de um dado recurso, e como podem ser inseridos numa proposta integral de trabalho (BRASIL, 1998; FREITAS, 2007; SOUZA, 2007). Segundo os PCN deve-se utilizar diferentes recursos didáticos de modo a permitir que o aluno tenha uma visão diferenciada e uma formação mais abrangente, tendo em vista que "é importante considerar que o livro didático não deve ser o único material a ser utilizado, pois a variedade de fontes de informação é que contribuirá para o aluno ter uma visão ampla do conhecimento" (BRASIL, 1998, p. 96). 
Pensando no potencial uso de uma sequência didática para trabalhar a educação ambiental, e na importância do provimento de ferramentas e meios que proporcionem auxílio à atividade docente, no que tange à abordagem de temas ambientais, a presente pesquisa teve como objetivo desenvolver uma SD abordando o tema impacto ambiental, organizada de forma adequada aos Parâmetros Curriculares Nacionais, envolvendo atividades práticas, transversais, contextualizadas e lúdicas, sendo destinada ao ensino fundamental. O processo envolveu identificar o interesse de docentes de diferentes áreas por um material de apoio às aulas, além de assuntos nos quais enfrentam dificuldades para abordar e gostariam de um suporte para trabalhá-los em sala de aula, e de conhecer suas opiniões sobre a SD desenvolvida.

\section{ASPECTOS METODOLÓGICOS}

O desenvolvimento da sequência didática decorreu de um subprojeto de um estudo maior concernente a uma pesquisa de dissertação de mestrado ${ }^{3}$, a qual teve dentre as suas finalidades a produção de um material didático de apoio aos docentes, apresentando temas ambientais de forma adequada aos PCN, organizado na forma de um guia prático de EA contendo um conjunto de sequências didáticas, dentre elas a SD impacto ambiental.

A pesquisa para a elaboração da SD teve natureza qualitativa (ALVES, 1991) e participante (GIL, 1999), sendo desenvolvida em três fases: 1) identificação dos interesses, dificuldades, perspectivas dos professores no trabalho em EA sob a ótica dos PCN (BRASIL, 1998); 2) escolha dos assuntos a serem abordados, pesquisa de recursos e metodologias, e elaboração da SD; 3) estudo da opinião dos docentes sobre a SD proposta.

Na primeira fase, contou-se com a participação de quinze professores atuantes no ensino fundamental, graduados em ciências biológicas, física, química e matemática, com a coleta de informações obtida por meio de um questionário contendo perguntas mistas (GIL, 1999). Com base nas respostas fornecidas partiu-se para a segunda fase da pesquisa, onde foram escolhidos os assuntos a serem abordados dentro do tema impacto ambiental, a partir da realização de pesquisas sobre recursos e metodologias que possibilitem abordá-los de forma definida pelos PCN (BRASIL, 1998); planejou-se a organização estrutural, didática e pedagógica da SD. Na terceira fase, a SD foi apresentada a cinco docentes, por meio de entrevistas individuais (CRESWELL, 2014), para obter opiniões preliminares, com a análise das informações provenientes das entrevistas e questionários empregando a análise textual discursiva (ATD) (MORAES; GALIAZZI, 2006).

Nesse artigo serão apresentados os resultados provenientes da segunda e terceira fase da pesquisa, havendo, quando necessário, comentários sobre resultados da primeira fase. A pesquisa foi aprovada pelo Comitê de Ética em Pesquisa, com os professores confirmando sua participação através da assinatura do Termo de Consentimento Livre e Esclarecido.

\section{DISCUTINDO OS RESULTADOS}

As respostas fornecidas pelos professores ao questionário revelaram as dificuldades que eles possuem em trabalhar a EA em suas aulas, e possibilitaram identificar temas de interesse, e o desejo por um material de apoio com atividades práticas, lúdicas e transversais. Este ferramental poderia, segundo eles, complementar o livro didático, o qual foi considerado contendo poucas atividades sobre o tema. Além disso, o material poderia auxiliar aqueles que não se sentem confortáveis ou preparados para abordar temas ambientais em suas aulas (JEOVANIO-SILVA; JEOVANIO-SILVA; CARDOSO, 2018). Os tópicos efeito estufa, degradação, erosão, desmatamento e poluição estão entre os assuntos citados pelos docentes, que foram classificados como conteúdos pertencentes ao tema impacto ambiental (ibidem).

3 Mestrado Profissional em Ensino de Ciências do Instituto Federal de Educação, Ciência e Tecnologia do Rio de Janeiro (IFRJ). 
Nessa perspectiva, a SD Impacto Ambiental foi desenvolvida contendo cinco etapas com objetivos distintos e atividades específicas, com sugestões de temas a serem abordados, os procedimentos para sua realização, os recursos necessários, além de material de apoio ou instruções. As cinco etapas foram intituladas: 1) cineminha ambiental sobre impacto nos ambientes; 2) poluição do ambiente terrestre; 3) o papel da vegetação no ambiente terrestre; 4) simulação do efeito estufa e 5) artistas do verde-mural ambiental. Cada uma das etapas se insere em uma das seguintes abordagens: de apresentação; técnica ou crítica. A abordagem de apresentação envolve uma introdução sobre o tema central da SD, a técnica visa a desenvolver no aluno a capacidade de identificar, questionar e propor soluções para os problemas ambientais discutidos, e a crítica tem a função de trabalhar a capacidade de observar questões ambientais de maneira contextualizada e integrada, unindo aspectos técnicos aos valores subjetivos.

O ideal é que todas as etapas (atividades) sejam realizadas, pois seu conjunto representa o desenvolvimento de diferentes fases de construção de saberes que são importantes a um crescente processo de interação e envolvimento emocional, valiosos aos processos de sensibilização e conscientização. Por outro lado, cada etapa foi idealizada para que possa ser aplicada de maneira independente, permitindo ao professor optar por realizar todas as etapas de SD ou selecionar aquelas que deseja trabalhar. Na impossibilidade de realizar as cinco etapas, sugerimos o desenvolvimento de, no mínimo, três etapas contemplando cada uma das abordagens nas quais elas podem se inserir.

De modo a fornecer um embasamento didático acerca das atividades presentes na SD, uma descrição das competências e habilidades trabalhadas no conjunto das etapas é apresentada aos docentes (Quadro 1). A SD foi organizada para uso no ensino fundamental II, podendo ser aplicada por professores de diversas áreas mediante a possibilidade de inclusão do tema proposto aos conteúdos das disciplinas, sendo disponibilizada na versão impressa e digital ${ }^{4}$.

\section{Quadro 1 - Descrição das competências e habilidades trabalhadas na sequência didática}

\begin{tabular}{|c|}
\hline \multicolumn{1}{|c|}{ Competências } \\
\hline Capacidade argumentativa; Capacidade analítica, crítica-reflexiva; Capacidade de trabalho em equipe; Capacidade de atuação social \\
\hline \multicolumn{1}{|c|}{ Habilidades } \\
\hline $\begin{array}{l}\text { Habilidade de compreensão dos conceitos; Habilidade de observação (acontecimentos, situações e comportamentos humanos); } \\
\text { Habilidade de identificação de aspectos positivos e negativos; Habilidade de comunicar/expressar suas ideias em público; } \\
\text { Habilidade de ouvir com atenção e compreender o comentário dos colegas; Habilidade de desenvolver as partes que lhe cabem } \\
\text { em tarefas dadas a um conjunto; Habilidade de desenvolver em conjunto tarefas dadas }\end{array}$ \\
\hline
\end{tabular}

Fonte: Adaptado de Orientações Curriculares e Subsídios Didáticos para a Organização do Trabalho Pedagógico no Ensino Fundamental de Nove Anos - Ciências da natureza (BAHIA, 2013).

A primeira etapa da SD, Cineminha ambiental sobre impacto nos ambientes, se insere na abordagem de apresentação, envolvendo os impactos ambientais causados pelas ações inadequadas do homem, tendo como recurso didático a apresentação de vídeo com posterior debate. O Quadro 2 apresenta a problemática, o objetivo geral, a sugestão de temas, as atividades previstas e a duração da etapa. 
Quadro 2 - Problemática, objetivo, temas, atividades e duração da primeira etapa da sequência didática, que possui abordagem de apresentação

\begin{tabular}{|l|l|}
\hline \multicolumn{2}{|c|}{ Primeira Etapa: Cineminha ambiental sobre o impacto nos ambientes } \\
\hline Problemática & $\begin{array}{l}\text { O planeta sofre com os impactos ambientais causados pelas ações inadequadas dos seres } \\
\text { humanos }\end{array}$ \\
\hline Objetivo geral & $\begin{array}{l}\text { Analisar danos causados ao ambiente por ações provocadas pelo ser humano visando } \\
\text { sensibilizar e conscientizar os alunos sobre a importância de cuidar do planeta }\end{array}$ \\
\hline $\begin{array}{l}\text { Sugestão de temas a serem } \\
\text { abordados }\end{array}$ & $\begin{array}{l}\text { Aquecimento global, poluição do ar, poluição do solo, poluição das águas, enchentes, } \\
\text { desmatamento, efeito estufa, derramamento de petróleo no mar, redução da biodiversidade, } \\
\text { monocultura, agricultura, pecuária, indústria extinção dos seres vivos, extinção das florestas, } \\
\text { lixo etc }\end{array}$ \\
\hline Atividades previstas & Exibição dos vídeos seguidos por debate orientado pelo professor \\
\hline Duração & Duas aulas de 50 minutos cada \\
\hline
\end{tabular}

Fonte: autores.

O vídeo é um recurso didático que vem sendo usado no ambiente escolar para introduzir conceitos, abordar e discutir assuntos, e mostrar imagens que muitas vezes não fazem parte da realidade de uma determinada população. Ele pode contribuir para facilitar o entendimento de um assunto, aprimorar outros, induzir a reflexão sobre um determinado tema, servir de base para iniciar debates, compartilhar costumes de povos com diferentes culturas, transmitir novos conhecimentos e informações dos mais diversos tipos (PIRES; ALMEIDA; MIRANDA, 2015). Segundo Moran (1995, p. 27), o vídeo "aproxima a sala de aula do cotidiano, das linguagens de aprendizagem e comunicação da sociedade urbana, e também introduz novas questões no processo educacional”, possibilitando que novos assuntos sejam abordados de maneira ampla e contextualizada.

O professor possui liberdade para selecionar os vídeos com os quais deseja trabalhar, contudo são indicados quatro vídeos ${ }^{5}$, com duração total de dezessete minutos. A proposta é que o docente realize um debate com a turma em relação as questões abordadas nos vídeos, sendo apresentada ao final da etapa a sugestão de perguntas ou tópicos para o debate.

A segunda, terceira e quarta etapas, de abordagem técnica, envolvem a realização de atividades experimentais, tradicionalmente utilizadas no ensino de disciplinas como ciências, biologia, química, física e geografia para demonstrar um determinado processo, além de facilitar a aprendizagem sobre um assunto específico. A partir de um experimento o aluno pode refletir sobre conceitos e fenômenos que ocorrem em seu meio e que são difíceis de serem imaginados. Segundo os PCN (1998, p. 122), é essencial que "as atividades práticas tenham garantido o espaço de reflexão, desenvolvimento e construção de ideias, ao lado de conhecimentos de procedimentos e atitudes".

As três etapas apresentam o roteiro para o desenvolvimento dos experimentos, tabelas para o aluno preencher ou perguntas para serem respondidas mediante o desenvolvimento da prática, assim como a indicação dos resultados esperados, de modo a auxiliar os professores que não estão familiarizados com a realização de aulas práticas ou que não conhecem o experimento proposto. O Quadro 3 apresenta a problemática, o objetivo geral, a sugestão de temas, as atividades previstas e a duração da segunda, terceira e quarta etapa.

Os impactos ambientais provenientes da poluição no ambiente terrestre são abordados na segunda etapa, Poluição do ambiente terrestre, cujo objetivo é trabalhar a influência de um poluente químico no processo de germinação, a partir da realização do experimento adaptado de Mattos e Porto (2006).

5 Vídeo 1: Sobre a semana nacional do meio ambiente. https://www.youtube.com/watch?v=GQcenZKsUYE

Vídeo 2: Sobre a semana nacional do meio ambiente - MMA https://www.youtube.com/watch?v=zHRVoEfP404

Vídeo 3: Vamos cuidar do ambiente. https://www.youtube.com/watch?v=pT8Oh4307F8\&list=PLBUtxH_s99AqvXtIja7Fvragau0-F4FgL\&index=3

Vídeo 4: Sobre sustentabilidade. https://www.youtube.com/watch?v=PWPidZDSkqw\&t=29s 
Já a terceira etapa, O papel da vegetação no ambiente terrestre, envolve a erosão do solo e os problemas de retenção provenientes da falta de cobertura vegetal, com atenção para a importância da presença da vegetação nas encostas quando da ocorrência de fortes chuvas. A proposta é que durante a realização da atividade experimental, adaptada de Gowdak e Martins (2001), termos como mata ciliar, desmatamento, desgaste do solo, deslizamento de terra, dentre outros, possam ser trabalhados com os alunos.

Quadro 3 - Problemática, objetivo, temas, atividades e duração da segunda, terceira e quarta etapas da sequência didática, que possuem abordagem técnica

\begin{tabular}{|c|c|}
\hline \multicolumn{2}{|r|}{ Segunda Etapa: Poluição do ambiente terrestre } \\
\hline Problemática & $\begin{array}{l}\text { A poluição é um dos impactos ambientais que pode atingir ambientes terrestres causando } \\
\text { consequências irreversíveis para este ambiente e para os seres que dependem dele para viver }\end{array}$ \\
\hline Objetivo geral & Observar a influência de um poluente químico (detergente) no processo da germinação \\
\hline $\begin{array}{l}\text { Sugestão de temas a serem } \\
\text { abordados }\end{array}$ & Poluição em ambientes terrestres e sua interferência na saúde vegetal; germinação \\
\hline Atividades previstas & $\begin{array}{l}\text { Realização de experimento para demonstrar a influência de um poluente químico sobre a } \\
\text { germinação }\end{array}$ \\
\hline Duração & Duas aulas de 50 minutos cada \\
\hline \multicolumn{2}{|r|}{ Terceira Etapa: $O$ papel da vegetação no ambiente terrestre } \\
\hline Problemática & A falta de cobertura vegetal expõe o solo à erosão e reduz a retenção \\
\hline Objetivo geral & $\begin{array}{l}\text { Demonstrar a importância da cobertura vegetal durante a ocorrência de fenômenos como } \\
\text { chuvas fortes e tempestades }\end{array}$ \\
\hline $\begin{array}{l}\text { Sugestão de temas a serem } \\
\text { abordados }\end{array}$ & $\begin{array}{l}\text { Mata ciliar, erosão, desgastes do solo, deslizamento de terra, vegetação nas encostas, equilíbrio } \\
\text { do solo }\end{array}$ \\
\hline Atividades previstas & Realização de experimento para demonstrar a importância da cobertura vegetal \\
\hline Duração & Duas aulas de 50 minutos cada \\
\hline \multicolumn{2}{|r|}{ Quarta Etapa: Simulação do efeito estufa } \\
\hline Problemática & $\begin{array}{l}\text { A emissão de grande quantidade de gases poluentes na atmosfera altera o fenômeno do efeito } \\
\text { estufa que ocorre no planeta e ocasiona o aquecimento global }\end{array}$ \\
\hline Objetivo geral & $\begin{array}{l}\text { Compreender o efeito estufa através de um experimento que simula o aquecimento do planeta } \\
\text { e conhecer as consequências desse aumento de temperatura para o ambiente e para a vida dos } \\
\text { seres vivos }\end{array}$ \\
\hline $\begin{array}{l}\text { Sugestão de temas a serem } \\
\text { abordados }\end{array}$ & $\begin{array}{l}\text { Aquecimento global, efeito estufa, emissão de poluentes na atmosfera, atividades humanas } \\
\text { relacionadas à emissão de poluentes na atmosfera }\end{array}$ \\
\hline Atividades previstas & Realização de experimento para demonstrar a importância do efeito estufa \\
\hline Duração & Duas aulas de 50 minutos cada \\
\hline
\end{tabular}

Fonte: autores.

O impacto dos gases poluentes na atmosfera é abordado na quarta etapa, Simulação do efeito estufa, cujo objetivo é que o aluno compreenda e conheça o efeito do aumento da temperatura para o ambiente, a partir do desenvolvimento de experimento adaptado de Faria (S/D).

A quinta etapa, Artistas do verde, é de abordagem crítica e tem como objetivo utilizar a arte como forma de contribuir para a sensibilização e conscientização dos estudantes quanto aos danos observados no ambiente, que são provenientes dos impactos ambientais. Como estratégia didática os alunos construirão um "mural ambiental" contendo fotos com áreas que apresentem danos ambientais. Nesta proposta, os alunos apresentam fotos de locais próximos de suas residências e da escola, prosseguindo-se a discussão e pesquisa bibliográfica acerca dos impactos ambientais. Ao final, o professor apresenta um roteiro para a elaboração do "mural ambiental" contendo propostas de soluções para os problemas identificados, formas de preservar ambientes, sensibilizando para mudanças de atitude por parte do estudante, de modo que possa atuar como multiplicador e transformador social, compartilhamento as informações obtidas no ambiente escolar e familiar. 
A contribuição e a importância das artes no processo de ensino e aprendizagem tem sido estudada, com diversas disciplinas passando a utilizar atividades artísticas no ensino (VILLAÇA, 2014). Além de diversificar as aulas, envolve o aluno fazendo-o ficar mais atento, desenvolve a criatividade, habilidades e competências, promove a comunicação com o subjetivo, com o emocional, estreita a interação entre os alunos, entre estes e o professor, torna as aulas mais dinâmicas e atrativas, promove a sensibilização e a ludicidade.

O Quadro 4 apresenta a problemática, o objetivo geral, a sugestão de temas, as atividades previstas e a duração da quinta etapa.

Quadro 4 - Problemática, objetivo, temas, atividades e duração da quinta etapa da sequência didática, que possui abordagem crítica

\begin{tabular}{|l|l|}
\hline \multicolumn{2}{|c|}{ Quinta Etapa: Artistas do verde } \\
\hline Problemática & $\begin{array}{l}\text { O ambiente vem sofrendo degradações como poluição das águas (rios, lagoas, mares, oceanos), } \\
\text { poluição do ar, resíduos jogados em diversos ambientes }\end{array}$ \\
\hline Objetivo geral & $\begin{array}{l}\text { Utilizar a arte para ajudar a promover a sensibilização e a conscientização das pessoas em } \\
\text { relação aos danos que o ambiente vem sofrendo através do comportamento do homem }\end{array}$ \\
\hline $\begin{array}{l}\text { Sugestão de temas a serem } \\
\text { abordados }\end{array}$ & $\begin{array}{l}\text { poluição das águas, poluição do ar, desmatamento, enchentes, queimadas e outros problemas } \\
\text { que afetam o ambiente }\end{array}$ \\
\hline Atividades previstas & Manifestação artística com exposição de fotos e imagens \\
\hline Duração & Duas aulas de 50 minutos cada \\
\hline
\end{tabular}

Fonte: autores.

Na avaliação da sequência didática os professores consideraram as etapas propostas bem elaboradas e detalhadas, contendo informações que permitem aos docentes realizá-las com facilidade e segurança, abordando conceitos diversos que fazem parte do conteúdo previsto para o ensino fundamental II.

Eu achei muito pertinente, muito boa. Porque eles pegam toda a parte do meio ambiente, água, solo, ar e resíduos. (Professor 2)

A etapa Poluição do ambiente terrestre foi considerada a mais interessante, seguida pelas etapas Papel da vegetação no ambiente terrestre, Cineminha ambiental e Artistas do verde, sendo a etapa Simulação do efeito estufa a menos indicada. Não houve a escolha de uma única etapa preferida, sugerindo que os professores aprovaram as atividades propostas na SD e as realizariam com satisfação em suas aulas, fato essencial à motivação docente e que pode influenciar na qualidade da aula e na interação aluno-professor.

Três professores afirmaram interesse em realizar todas as etapas da SD, enquanto dois indicaram que fariam apenas algumas das etapas propostas apresentando a falta de tempo como justificativa, refletindo a realidade vivenciada por muitos docentes tanto da rede pública quanto da privada. Um dos elementos que provavelmente contribuiu para a aceitação das etapas foi o fato de os assuntos escolhidos serem atuais e presentes no conteúdo do nível fundamental II.

Eu acho que daria para fazer todas porque são temas abrangentes que a gente acaba lidando no dia a dia. (Professor 3)

Eu faria com certeza o papel da vegetação no ambiente terrestre. A do experimento com detergente eu também faria. Simples de fazer e dá para fazer em sala de aula mesmo sem um laboratório. Então eu consigo fazer. Nessa parte de impacto ambiental tem muitos vídeos interessantes para a gente abordar. (Professor 4)

Em relação aos aspectos didáticos e pedagógicos, quatro docentes consideraram que as habilidades e competências foram apresentadas com clareza, e todos relataram que as etapas possuem objetivo bem descrito 
e relevante. Em relação aos materiais e recursos necessários ao desenvolvimento das etapas, todos concordaram que estavam descritos de forma clara e de fácil entendimento, com as atividades propostas sendo apontadas como de fácil realização possuindo procedimentos explicativos e bem descritos.

Conforme Czapski (1998), a EA é uma peça essencial para a melhora das atitudes das pessoas em relação ao ambiente onde vivem. Este é o entendimento preconizado pelos PCN (BRASIL, 1998), que definem que a EA deve ser abordada obrigatoriamente e de maneira específica, de forma que, em uma conjuntura ideal, seria esperado que todo professor aborde, em algum momento, questões em EA. Nesse ínterim, de posse da avaliação positiva da SD pelos docentes, e considerando a maneira como ela foi organizada, identifica-se que a SD pode ser empregada por docentes de diferentes áreas, possibilitando que os temas envolvendo impactos ambientais sejam abordados de forma lúdica, contextualizada, transversal e crítica, conforme preconizado pelos PCN.

\section{CONSIDERAÇÕES FINAIS}

A educação ambiental é prevista e determinada por lei, sendo definida como uma forma de se estabelecer valores e atitudes fundamentais para a conservação do meio ambiente. Consideramos que trabalhar a temática ambiental desde o ensino fundamental é um eficiente caminho para a conscientização e sensibilização das crianças, que logo atuarão como indivíduos ativos na sociedade. Nessa perspectiva, apresentamos o desenvolvimento e a avaliação de uma sequência didática sobre impacto ambiental, abordando questões sobre a poluição das águas, do solo e do ar, erosão, aumento do efeito estufa, descarte inadequado dos resíduos sólidos e desperdício de água, organizada de modo a tender aos interesses, dúvidas e perspectivas dos professores, facilitando uma abordagem transversal a partir de atividades lúdicas e contextualizadas sob um olhar crítico e reflexivo.

A boa avaliação da sequência didática por parte dos docentes demonstra seu potencial como material didático suplementar, sendo considerada de fácil utilização por professores de diferentes áreas, o que amplia sua perspectiva de uso como instrumento de trabalho em uma perspectiva transversal. A satisfação com as atividades propostas, o que consideramos essencial à motivação docente, se refletirá na qualidade da aula e na interação aluno-professor, e que deve ser mantida como um objetivo essencial a se buscar na elaboração de uma sequência didática, pois representa ter uma visão integral do processo de ensino-aprendizagem considerando diferentes atores e aspectos envolvidos no processo.

Uma sequência didática que seja considerada atrativa ao docente, tanto por aspectos diretamente direcionados a ele quanto aqueles voltados ao estudante, confere à sequência um grande potencial para o auxílio na realização de atividades que contribuam no despertar da sensibilidade e conscientização necessários para que ocorram as mudanças de atitudes, comportamentos e valores de alunos, professores e da sociedade como um todo. Dessa forma, tais SD, na qual inserimos a sequência didática Impacto Ambiental, seriam úteis no processo de construção de transformadores sociais, de indivíduos com visão ampla, integral, balizados em princípios do ecologicamente correto e da sustentabilidade dos ecossistemas, que busquem lidar com as questões ambientais de maneira não antropocêntrica. 


\section{REFERÊNCIAS}

ALVES, A. J. O Planejamento de pesquisas qualitativas em educação. Caderno de pesquisa. São Paulo, n. 77, p. 53-61, 1991.

BAHIA. Orientações Curriculares e Subsídios Didáticos para a Organização do Trabalho Pedagógico no Ensino Fundamental de Nove Anos, Secretaria de Educação. 2013. Disponível em:<http://docplayer.com.br/5816855Orientacoes-curriculares-e-subsidios-didaticos-para-a-organizacao-do-trabalho-pedagogico-no-ensino-fundamental-denove-anos.html>. Acesso em: 08 de mai. 2017.

BRASIL. Resolução Conama No 001, de 23 de janeiro de 1986. Disponível em:<http://www.mma.gov.br/port/conama/ legislacao/CONAMA_RES_CONS_1986_001.pdf>.Acesso em: 15 de fev. 2018.

BRASIL. Parâmetros Curriculares Nacionais: terceiro e quarto ciclos: apresentação dos temas transversais / Secretaria de Educação Fundamental. - Brasília: MEC/SEF, 1998. Disponível em: <http://portal.mec.gov.br/seb/arquivos/pdf/ ciencias.pdf>. Acesso em: 23 de abr. 2017.

CZAPSKI, S. A implantação da EA no Brasil. Brasília: MEC, 1998.

CRESWELL, J. W. Investigação Qualitativa e Projeto de Pesquisa. Escolhendo entre cinco abordagens. 3.ed. Porto Alegre: Penso, 2014.

FARIA, I. D. Ciências a mão. Simulador do efeito estufa. (S/D). Disponível em: <http://www.cienciamao.usp.br/tudo/ exibir.php?midia=lcn\&cod=_geocienciassimuladordoef $>$. Acesso em: 10 de fev. 2017.

FREITAS, O. Equipamentos e materiais didáticos. Universidade de Brasília - UNB. 2007. Disponível em:<http:// portal.mec.gov.br/seb/arquivos/pdf/profunc/equip_mat_dit.pdf>. Acesso em: 15 de fev. 2017.

GIL, A. C. Métodos e técnicas de pesquisa social. 5.ed. São Paulo: Atlas, 1999.

GOWDAK, D.; MARTINS, E. Ciências novo pensar. 5ª série. 1.ed. São Paulo: FTD, 2001.

JEOVANIO-SILVA, V. R. M; JEOVANIO-SILVA, A. L.; CARDOSO, S. P. Um olhar docente sobre as dificuldades do trabalho da educação ambiental na escola. Revista de Ensino de Ciências e Matemática, v. 9, n. 5, p. 256-272, 2018.

MATTOS, N. S.; PORTO, D. P. Projeto Radix: ciências. 5ª série. 1.ed. Rio de Janeiro: Scipione, 2006.

MORAES, R; GALIAZZI, M. C. Análise Textual Discursiva: Processo reconstrutivo de múltiplas faces. Ciência \& Educação. v. 12, n. 1, p. 117-129, 2006.

MORAN, J. M. O vídeo na sala de aula. Comunicação e Educação, São Paulo, v. 2, p. 27-35, 1995.

OLIVEIRA, M. M. Sequência Didática interativa no processo de formação de professores. São Paulo: Vozes, 2013.

PIRES, T. C.; ALMEIDA, A. G.; MIRANDA, C. Sessão de cinema: estratégia metodológica para a construção e socialização do saber na perspectiva da educação para as relações étnico-raciais. In: X Encontro regional nordeste de história oral, Salvador, 2015.

SOUZA, S. E. O Uso de Recursos Didáticos no ensino escolar. I Encontro de Pesquisa em Educação, IV Jornada de Prática de Ensino, XIII Semana de Pedagogia da UEM: “Infância e Práticas Educativas”. Arq Mudi.11(Supl.2). 2007.

VILLAÇA, I. de C. Arte-Educação: a arte como metodologia educativa. Cairu em Revista. Ano 3. n. 4. p. 74-85, 2014. 